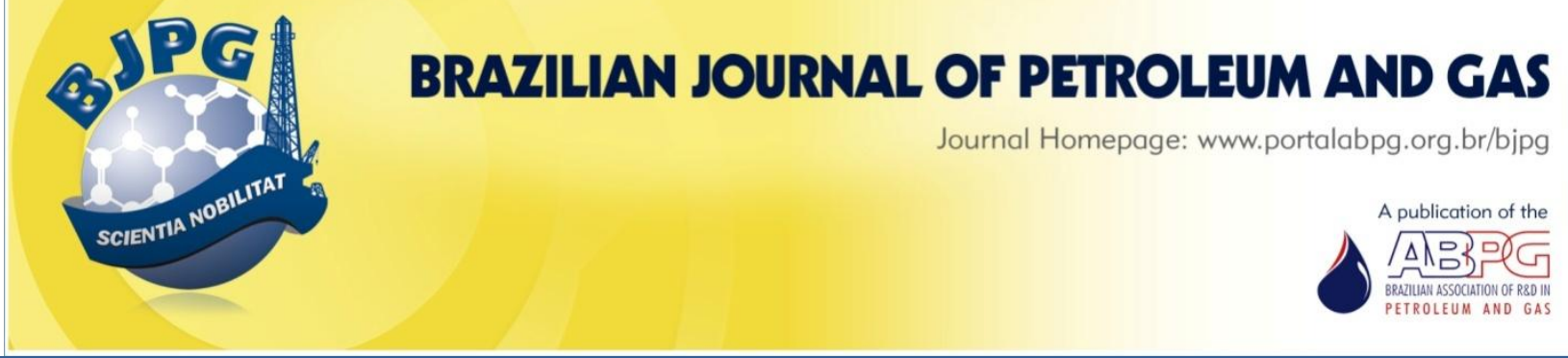

\title{
REALISTIC OPTIMIZATION OF WELL LENGTH FOR HORIZONTAL DRILLING
}

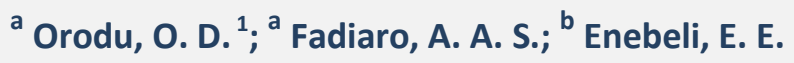 \\ a Department of Petroleum Engineering, Covenant University, Ogun State, Nigeria \\ ${ }^{\mathrm{b}}$ School of Economics \& Management, China University of Geosciences, Wuhan, China
}

\begin{abstract}
Evaluation of optimal drain-hole length for horizontal wells in the past, under the condition of pressure drop between the toe and heel of the well, has neglected some vital variables. These include drain hole diameter as a parameter in the objective function, diameter of vertical section for well deliverability consideration, and the composite pressure drop of the well as a system. The length was optimized based on net present value as the objective function (Case-1), flow rate (Case-2) and vertical well pressure drop with constant bottom-hole flowing pressure (Case-3). Optimizing drain-hole length requires more than adjusting variables that improve inflow performance to maximize return-on-investment. The optimization process demands the observation of spectrum of variables/events that are influenced by the dynamic nature of production as relates to fluid property and composite pressure of the entire well and reservoir system. A holistic approach, considering the inflow (entire horizontal section acting as oil inflow source) and vertical lift performance is paramount, focusing on flow resistivity in the drain hole.
\end{abstract}

\section{KEYWORDS}

horizontal well; optimization; drain-hole length; flow resistance; net present value

\footnotetext{
${ }^{1}$ To whom all correspondence should be addressed.

Address: Department of Petroleum Engineering, School of Engineering, College of Science \& Technology, Km. 10 Idiroko Road, Ota, Ogun State, Nigeria

Telephone: +234 (0) 7061132990 | E-mail: david.orodu@covenantuniversity.edu.ng, preye.d.orodu@gmail.com doi:10.5419/bjpg2012-0005
} 


\section{INTRODUCTION}

The pros and cons of a horizontal well have been enumerated. This work covers its limitation to zones to drain and its application to achieve high productive index (PI), gas and water coning reduction, and recovery from fractured and low permeability reservoir. These areas of relevance are linked to increased drainage area. Moreover, increased $\mathrm{Pl}$ is associated with the horizontal drain hole length.

Cho and Shah (2002) optimized the horizontal length based on maximizing net present value (NPV) by considering the frictional pressure drop along the drain hole with regards to the finite conductivity concept that was developed by Dikken (1990). The concept negates uniform flow in the horizontal drain hole. Fadairo et al. (2011) further included other pressure drops (pressure drop due to accumulation and kinetic energy) to account for transient flow period. They were also able to predict the influence of both drain-hole length and diameter on PI. However, the transient flow period is short compared to the entire life of production of a well since the effect is only pronounced at the onset of production. Therefore, for economic analysis, the disparity in prediction of PI between that of Cho and Shah (2002) and Fadairo et al. (2011) is insignificant. For a particular drain hole diameter, increasing length is detrimental to maximizing returns on investment at a certain point in regards to decreased productivity and hence production rate. Though, reservoir contact of a drain hole has been known to extend to $4000 \mathrm{ft}$ (Bosio et al., 1987). It has been shown also that optimum ratio of diameter to drain hole length should be considered during horizontal well planning in order to compensate for the frictional pressure drop (Fadairo et al., 2011). The critical parameters to enhancing production are drain hole length, drain hole diameter, drawdown, horizontal permeability, and production rate as it influences frictional pressure drop when not assuming infinite conductivity of the drain hole as this connotes vertical well's inflow performance having increased drainage area.

Dikken's analytical solution and Arps' decline model as applicable to horizontal well production aided production prediction with time for optimal well length computation (Dikken, 1990). The dependence of the variables or the inter- relationship amongst the variables affecting production does not limit the use of only drain hole length as the only parameter to optimize production with respect to maximizing return on investment. In addition, the interplay of drain hole inflow performance, assuming the entire length is in communication with the reservoir and the vertical lift performance (VLP) of the vertical section of the horizontal well is vital in optimizing production economically based on the dynamic nature of all the forces at play. Thus, well deliverability in terms of diameter of the vertical section tubing or cased hole is imperative as regards friction since this most compliment optimal diameter and length of the horizontal drain hole.

\section{OPTIMAL LENGTH}

\subsection{Production analysis}

Arps' hyperbolic decline model is applied to forecast of oil rate, though other decline models such as exponential and harmonic models are equally applicable to production from horizontal wells. Nevertheless, production trend analysis does determine which of the model is suitable. In this instance, hyperbolic decline is assumed with a decline exponent " $b$ " of 0.667 . Equation (1) is the production rate at any time and Equation (2) is the cumulative produced oil obtained by integrating the previous equation for a time interval. By using an abandonment oil rate, the decline rate is computed from Eq. (2) for given cumulative produced oil and initial oil production obtained Dikken's sophisticated analytical model. Whereas produced time till well abandonment is computed from Eq. (2).

$q=q_{i}\left(1+b D_{i} t\right)^{-1 / b}$

$$
N_{p}=\frac{q_{i}}{(1-b) D_{i}}\left[1-\left(\frac{q}{q_{i}}\right)^{1-b}\right]
$$

Where, $b$ is the decline exponent; $D_{i}$, decline rate; $N p$, cumulative production; $q_{i}$, initial 
production rate; and $q$, production rate at time $t$.

Initial production is based on the analytical model solely (Equation 3) of Renard and Dupuy (1991) for a horizontal well. The model was derived for steady state flow without flow resistance by assuming infinite conductivity of the drain hole. Application of the model is modified as applied in Cho and Shah (2002) by considering flow resistance (Equations 8-10) as formulated by Dikken (1990).

The approach to computing initial flow rate with flow resistance is to first calculate the flow rate without flow resistance from Equation (3). Then, calculate the flow resistance $(R s)$ from Equation (8) and the productivity index per unit length. Finally, flow rate can be calculated with flow resistance (Equation 9 and 10).

$$
q^{\prime}=\frac{0.007078 k_{h} h \frac{\Delta P_{h}}{\mu B_{o}}}{\cosh ^{-1}(X)+\frac{\beta h}{L_{h}} \ln \frac{h}{2 \pi r_{w}^{\prime}}}(\text { stb/ day })
$$

where,

$$
\beta=\sqrt{k_{h} / k_{v}}
$$

$\cosh ^{-1}(X)=\ln \left[\frac{a+\sqrt{a^{2}-\left(L_{h} / 2\right)^{2}}}{L_{h} / 2}\right]$

$a=\frac{L_{h}}{2}\left[0.5+\sqrt{0.25+\left(2 \mathrm{R}_{\mathrm{e} h} / L_{h}\right)^{4}}\right]^{0.25}$

$$
\begin{aligned}
& r_{w}^{\prime}=\left(\frac{1+\beta}{2 \beta}\right) r_{w} \\
& R_{s}=2.921 \times 10^{-15} L_{h}^{1.86}\left(\frac{\mu_{o} D_{h}}{\rho}\right)^{\alpha} \frac{\rho}{\pi^{1.75} D_{h}{ }^{5}}
\end{aligned}
$$

$$
J_{s}(x)=\frac{q^{\prime} B_{o}}{\Delta P_{h} L_{h}}(r b / \text { psi.day.ft })
$$

$$
q_{x=0}=\frac{J_{s}(x) \Delta P_{h}\left(L_{h}-x\right)}{\cosh \left(L_{h} \sqrt{J_{s}(x) R_{s}}\right)}
$$

Where $a$ is half major axis of drainage ellipse; $B_{o}$, oil formation volume factor; $D_{h}$, drain hole diameter; $h$ (ft), formation thickness; $J_{s}(x)$, productivity index per unit length; $k_{h}(\mathrm{md})$, horizontal permeability; $k_{v}$ (md), vertical permeability; $L_{h}(\mathrm{ft})$, drain hole length; $q$ ', oil production rate without friction loss; $q$, oil production rate with friction loss; $R s$, flow resistance of the drain hole; $r_{w}(\mathrm{ft})$, wellbore radius; $r_{w}^{\prime}(\mathrm{ft})$, effective wellbore radius in anisotropic; $R_{e h}$, horizontal well drainage radius; $\Delta P_{h}$ (psi), drawdown at the heel of the well; $\alpha$, empirical coefficient for flow resistance; $\beta$, anisotropy; $\rho$, oil density; $\mu_{o}(\mathrm{cp})$, oil viscosity; and $\pi$, pi.

\subsection{Pressure drop vertical section}

The study also couples vertical pressure at optimizing the drain hole length and diameter, with the diameter of the tubing/casing in the vertical direction. The pressure drop in the vertical direction comprises of the potential energy and friction loss. Potential energy is constant for all pipe diameters, except that of friction loss. Fluid density and formation volume factor are assumed constant for simplification; hence, the difference between the bottom hole flowing pressure and tubing head flowing pressure is equal to the pressure drop (Equation 11 and 12). 
$P_{w f}-P_{t f}=\Delta P_{P E}+\Delta P_{f}$

$\Delta P_{P E}+\Delta P_{f}=\frac{\rho_{o} L_{v}}{144}+\frac{f \rho_{o} V^{2} L_{v}}{2 g_{c} D_{v}}\left(\frac{1}{144}\right)$

$P_{w f}-P_{t f}=\frac{\rho_{o} L_{v}}{144}\left(1+\frac{f V^{2}}{2 g_{c} D_{v}}\right)$

Where,

$V=0.011915 \frac{q}{D_{v}^{2}}$

$f=0.25\left[1.14-2 \log \left(\varepsilon / D_{v}+21.25 N_{\mathrm{Re}}^{-0.9}\right)\right]^{-2}$

$N_{\mathrm{Re}}=0.1231 q \rho / \mu_{o} D_{v}$

$q$ in (bbl/day), $\mu_{o}(\mathrm{cp}), D_{v}(\mathrm{ft})$ and $\rho\left(\mathrm{lb}_{\mathrm{m}} / \mathrm{ft}^{3}\right)$. Where $L_{v}(\mathrm{ft})$ is the vertical section of horizontal well; $D_{v}$ (in.), diameter of vertical section; $V(\mathrm{ft} / \mathrm{s})$, vertical section flow velocity; $q$ (bbl/day), flow rate; $f$, Darcy-Weisbach (Moody) friction factor; $g_{c}$, conversion factor; $\rho_{o}\left(\mathrm{lbm} / \mathrm{ft}^{3}\right)$, oil density; $N_{R E}$, Reynolds number; $P_{w f},(\mathrm{psi})$, bottom hole flowing pressure at heel; $P_{t f}$, tubing head flowing pressure; $\Delta P_{P E}$, potential energy; $\Delta P_{f}$, friction loss; and $\varepsilon$, relative roughness.

\subsection{Economic analysis}

NPV (Net Present Value) has traditionally been used for assessing the profitability of a project or field development concept. Therefore, for this purpose, NPV shall serve as the objective function to maximize drain hole length. Cash flows from revenue and expenditure are discounted. All analysis in this study shall be before tax. Prior economic evaluation for optimal drain-hole length is based on the fundamentals of Equation (14). Best estimates of variables making up the objective function shall be used. This is a deterministic approach. Uncertain variables that may demand stochastic evaluation are oil price, discount rate, and some basic reservoir parameters such as horizontal and vertical permeability, and formation height.

$\sum \mathrm{NCF}=\sum$ Revenue $-\sum$ Construction -

$-\sum$ Operating Cost $-\sum$ Overhead $-\sum$ Capital

Where NCF is the net cash flow.

The equation below shall be adapted to maximize well length as against the former. Well construction costs shall fall under capital expenditure (CAPEX), and operating costs and overhead costs shall both fall under variable and fixed operating expenditure (OPEX). This is in accordance with the formulation for optimal sidetrack time evaluation in Orodu et al. (2011).

$\sum \mathrm{NCF}=\sum$ Revenue $-\sum \mathrm{CAPEX}($ well construction cost $)-\sum$ Variable OPEX -

$-\sum$ Fixed OPEX

Where, NCF is defined in Equation (14).

\subsubsection{Revenue}

Revenue accruable to production is the product of oil price and production rate at a particular time,

Revenue $=$ Oil Price $\times$ Production Rate $\times$

$\times$ time $=P o \times q$

Revenue over an interval with production rate being a function of time is computed as given below. 
Revenue over an interval $=P o \times q \times d t$

Revenue $($ discounted $)=P o \times q \times$

$\times \exp \left(-i_{d} \times t\right) \times d t$

Where, $i_{d}$ is discount rate; $P o$, oil price; $q$, oil production rate; and $t$, time.

Revenue (discounted), finite interval $=$

$=\int P o q \mathrm{e}^{-i d t} d t$

Where, $q=q_{i}\left(1+b D_{i} t\right)^{-1 / b}$

Revenue (discounted), finite interval =

$=\int P o q_{\mathrm{i}}\left(1+b D_{i} t\right)^{-1 / b} \mathrm{e}^{-i d t} d t$

$\mathrm{q}_{\mathrm{i}}=\mathrm{f}\left(L_{h}, D_{h}, \mathrm{k}_{\mathrm{h}}, \mathrm{k}_{\mathrm{v}}, \ldots \ldots \ldots \ldots \ldots \ldots \ldots\right)$

Where, $L_{h}, D_{h}, k_{h}$ and $k_{v}$ are as previously defined. Production rate depends on the variables enumerated above, however, previous study by Cho and Shah (2002) had evaluated optimal drain hole length without considering the fundamental relationship between the variables that impact production as well as NPV.

\subsubsection{Fixed OPEX}

The fixed OPEX is calculated in percent per year (or month) of initial investment in the form of CAPEX,

Fixed OPEX $=3 \% / \mathrm{yr} \times \mathrm{CAPEX}$

Fixed OPEX over an interval $=$

$=\gamma \times \mathrm{CAPEX} \times d t$

Fixed OPEX $($ discounted $)=$

$=\gamma \times \operatorname{CAPEX} \times \mathrm{e}^{-i d t} d t$
Where, $\alpha$ is variable oil production cost.

Variable OPEX over an interval $=\alpha \times q \times d t$

Fixed OPEX (discounted), finite interval =

$=\gamma \times \operatorname{CAPEX} \times \int \mathrm{e}^{-i d t} d t$

Where, $\gamma$ is fixed production cost multiplier per year.

\subsubsection{Variable OPEX}

Variable OPEX incorporates facility handling charges and is a fraction of produced oil in the form of cost per barrel,

Variable OPEX $=\alpha \times q$

Variable OPEX $($ discounted $)=$

$=\alpha \times q \times \exp \left(-i_{d} \times t\right) \times d t$

Variable OPEX (discounted),

finite interval $=\alpha \int q \mathrm{e}^{-i d t} d t$

Variable OPEX (discounted),

finite interval $=\alpha q_{\mathrm{i}} \int\left(1+b D_{i} t\right)^{-1 / b} \mathrm{e}^{-i d t} d t$

\subsubsection{CAPEX}

Well construction cost comprises the vertical and horizontal well sections and makes up the construction cost. An appropriate method entails the use of cost of bit, rig cost and time, along with drilling and completion cost per length for a particular well program under study. An empirical equation obtained from past well construction estimates is utilized as in Cho and Shah (2002).

CAPEX, which represents the well construction cost, is the sum for the vertical and horizontal 
sections as given below:

$\mathrm{CAPEX}=\mathrm{C}_{\mathrm{v}}+\mathrm{C}_{\mathrm{h}}$

Costs in terms of the individual components that make up the final cost is,

$\mathrm{C}_{\mathrm{v}}+\mathrm{C}_{\mathrm{h}}=\left\{\left(\mathrm{C}_{\mathrm{bev}}+\mathrm{C}_{\mathrm{r}} \mathrm{t}_{\mathrm{lv}}+\mathrm{C}_{\mathrm{cpv}}\right) / \mathrm{L}_{\mathrm{v}}\right\}+$

$+\left\{\left(\mathrm{C}_{\mathrm{beh}}+\mathrm{C}_{\mathrm{r}} \mathrm{t}_{\mathrm{lh}}+\mathrm{C}_{\mathrm{cph}}\right) / \mathrm{L}_{\mathrm{h}}\right\}$

Where $C_{b e v}$ is the cost of bits for the vertical section; $\mathrm{C}_{\mathrm{beh}}$, is the cost of bits for the horizontal section; $\mathrm{Cr}$, is the rig cost; $\mathrm{C}_{\mathrm{cpv}}$, is the well completion cost for the vertical section; $\mathrm{C}_{\mathrm{cph}}$, is the well completion for the cost horizontal section; $t_{\mathrm{lv}}$, is the time for vertical section drilling, and $t_{l h}$, is the time for the vertical section drilling.

The empirical equation is obtained from the regression analysis of a plot of drilling cost against vertical depth that is based on data available. Then, vertical section cost is:
$\mathrm{C}_{\mathrm{v}}(\mathrm{USD})=0.03 \mathrm{~L}_{\mathrm{v}}+29.8$

Whereas for horizontal section,

$\mathrm{C}_{\mathrm{h}}(\mathrm{USD})=\mathrm{A} \times \mathrm{L}_{\mathrm{h}}^{\mathrm{n}}+\mathrm{B}$

Where A is unit construction cost; $\mathrm{B}$, fixed cost; and $\mathrm{n}$, construction cost exponent.

\subsubsection{NPV}

The net present value (Equation 20) is the discounted net cash flow (NCF) of Equation (15). Continuous discount rate is used.

$$
\begin{aligned}
& N P V=(P o-\alpha) q_{i} \int_{0}^{t}(1+b D t)^{-1 / b} e^{-i_{D} t} d t- \\
& -\left(C_{v}+C_{h}\right)\left[1+\gamma \int_{0}^{t} e^{-i_{D} t} d t\right]
\end{aligned}
$$

Where $q_{\mathrm{i}}$ is from Equation (10), that inherently constitute Equations $3-9$.

\begin{tabular}{|c|c|c|c|}
\hline Boundary Pressure & $\boldsymbol{P}_{e}$ & 3000 & psia \\
\hline Drawdown pressure & $\Delta P$ & 150 & psi \\
\hline Bottom hole flowing pressure & $\boldsymbol{P}_{w f}$ & 2850 & psi \\
\hline Tubing head flowing pressure & $P_{t f}$ & 150 & psi \\
\hline Oil Viscosity & $\mu_{o}$ & 1 & $\mathbf{c p}$ \\
\hline Effective roughness & $\varepsilon / D$ & 0.1 & \\
\hline Oil formation volume factor & $\boldsymbol{B}_{o}$ & 1.2 & $\mathrm{rb} / \mathrm{stb}$ \\
\hline Horizontal permeability & $\mathbf{k}_{\mathbf{h}}$ & 20 & md \\
\hline Vertical permeability & $\mathbf{k}_{\mathrm{v}}$ & 2 & md \\
\hline Vertical drainage area & $A_{v}$ & 32 & acre \\
\hline Drainage type & & & elliptical \\
\hline Drain hole length & $L_{h}$ & 4000 & $\mathrm{ft}$ \\
\hline Drain hole diameter & $D_{h}$ & 6 & in. \\
\hline Fluid density & $\rho$ & 53.1 & $\mathrm{lbm} / \mathrm{ft}^{3}$ \\
\hline Formation thickness & $h$ & 50 & $\mathrm{ft}$ \\
\hline Skin factor & $s$ & 0 & \\
\hline Empirical coefficient & $\alpha$ & 0.25 & \\
\hline Porosity & $\varphi$ & 0.16 & \\
\hline Recovery factor & $\boldsymbol{R}_{F}$ & 0.25 & \\
\hline Oil Saturation & $S_{o i}$ & 0.75 & \\
\hline Connate Water Saturation & $S_{w c}$ & 0.25 & \\
\hline Cumulative oil production & $N_{P}$ & 5.79 & mmbbl \\
\hline
\end{tabular}

Table 1. Fluid and reservoir properties. 
Table 2. Optimal drain-hole length and NPV.

\begin{tabular}{lll}
\hline Drain-hole Diameter (in) & $L_{h}(\mathrm{ft})$ & NPV (USD mm) \\
\hline 2.375 & 2366.01 & 121.267 \\
3.000 & 3169.17 & 144.494 \\
4.090 & 4554.82 & 174.833 \\
4.920 & 5547.93 & 191.185 \\
5.012 & 5666.69 & 192.618 \\
6.049 & 6809.63 & 206.121 \\
6.299 & 7012.91 & 208.715 \\
\hline
\end{tabular}

\subsection{0ptimization}

The study is conducted in 3 ways:

\section{Case-1:}

NPV, the objective function of Equation (20) is maximized using a non-linear optimization code in spreadsheet. Constraints include drain-hole diameter not exceeding a given value and drainhole length being greater than $1000 \mathrm{ft}$.

\section{Case-2:}

For a given drain-hole diameter, NPV and initial production rate is computed for incremental drainhole length between $1000 \mathrm{ft}$ and $9000 \mathrm{ft}$. In addition, since pressure drop due to potential energy is constant for all pipe diameters for well deliverability in the vertical section of the horizontal well, the friction loss in the vertical section of the well is computed for different flow rate for inflow performance adjusted by drain-hole diameter considerations.

\section{Case-3:}

The objective function (Equation 13a) is optimized to achieve a set target that is the difference between the bottom hole flowing pressure and the tubing head flowing pressure, which are fixed for this purpose. Hence, drain-hole length is optimized for a given set of drain-hole diameter and vertical well section deliverability diameter. Flow velocity (Equation 13b) in the vertical section is dependent on the flow rate emanating from the drain-hole, which is controlled by the drain-hole length and diameter. Results shall be presented in a matrix and accompanied by a graph for ease of interpretation. In addition, Equation (20) an objection function with regards to NPV is optimized and subjected to Equation (13b) as a constraint.

Optimization is made possible in a spreadsheet using a generalized reduced gradient non-linear optimization code.

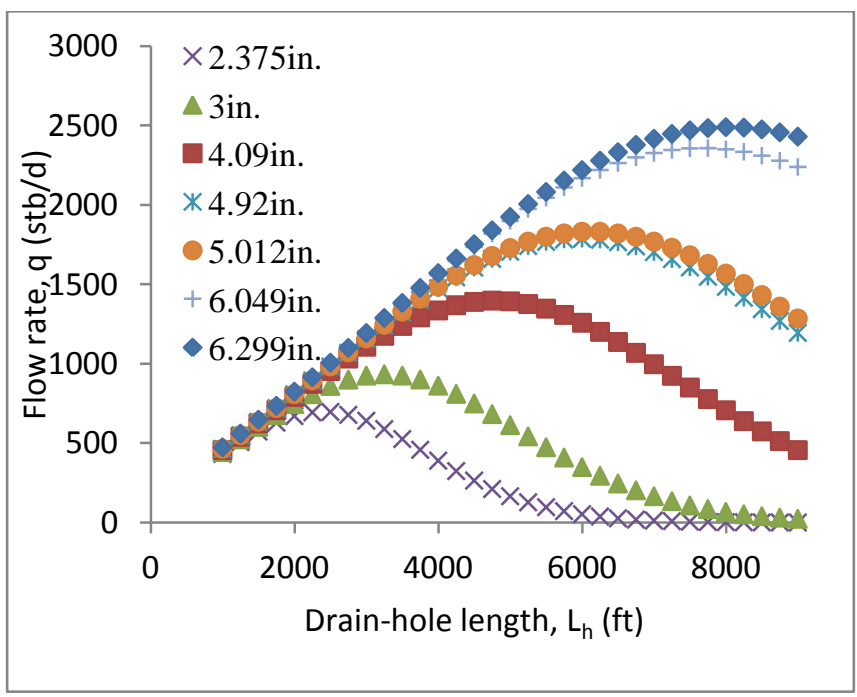

Figure 1. Effect of drain-hole diameter on the plot of flow rate based on inflow performance with friction loss against drain-hole length. 


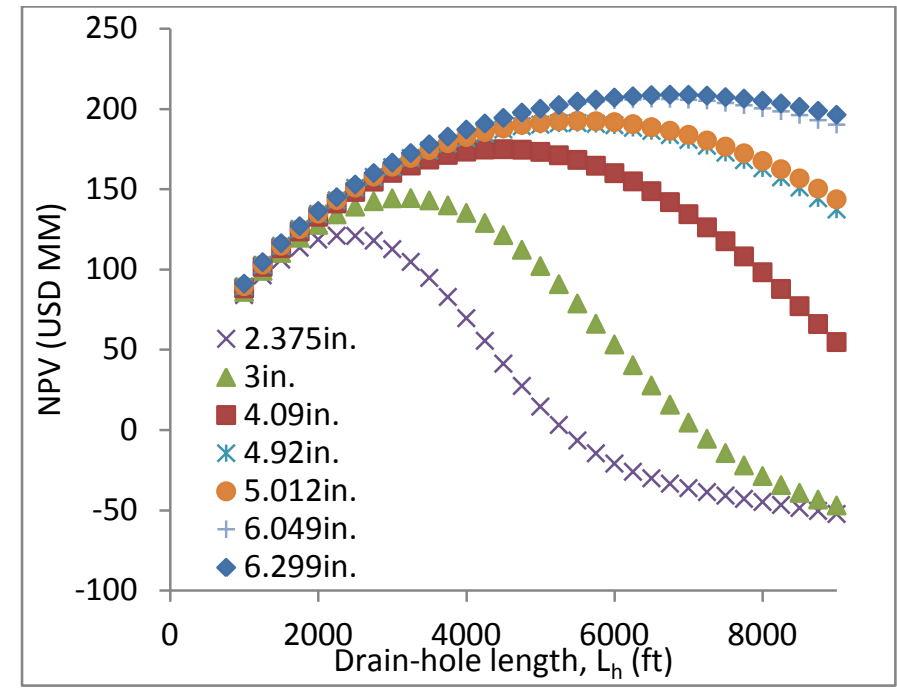

Figure 2. Effect of drain-hole diameter on the plot of NPV based on oil flow rate against drain-hole length.

\section{RESULTS AND DISCUSSION}

Data used for this study are as seen in Table 1 (Cho and Shah, 2002; Fadiaro et al., 2011). The cumulative oil production possible is based on recoverable reserves from recovery factor estimate (Fetkovich, 1973).

Case-1: The NPV objective function of Equation (20) is optimized with the major constraint of maximum allowable drain-hole diameter fixed at 2.375in, 3in, 4.09in, 4.92in, 5.012in, 6.049in, and 6.299in, with results of optimal drain-hole length and corresponding NPV shown in Table 2. The NPV function was particularly subject to the drain-hole length and drain-hole diameter, but length was the only variable. It appears that the optimal flow rate for a particular drain-hole diameter is directly proportional to the combination of drain-hole length " $L_{h}$ " and diameter " $D_{h}$ ". At low flow rate, $D_{h}$ is insignificant due to low/negligible friction loss and its influence increases until the effect of $L_{h}$ dominates leading to decline in flow rate at an optimal oil flow rate (Figure 1). This trend is repeated on the NPV plot (Figure 2) with a bell shape similar to normal probability distribution.

Case-2: Optimal oil production rate from the previous maximization step at different drain-hole diameter inflow performance at incremental drainhole length is used to compute friction loss in the vertical section to obtain well deliverability status. For inflow performance and vertical performance to be optimized, pressure should be minimal. In

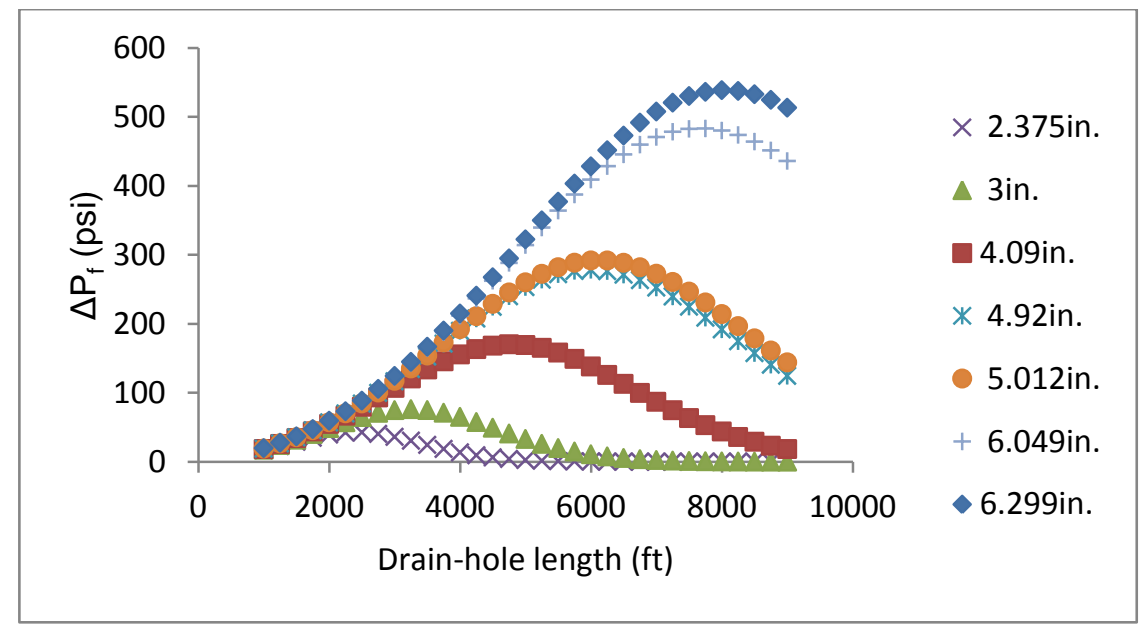

Figure 3. Friction pressure loss in 2.375 in vertical section hole for various drain-hole diameter inflow performance at increasing drain-hole length. 


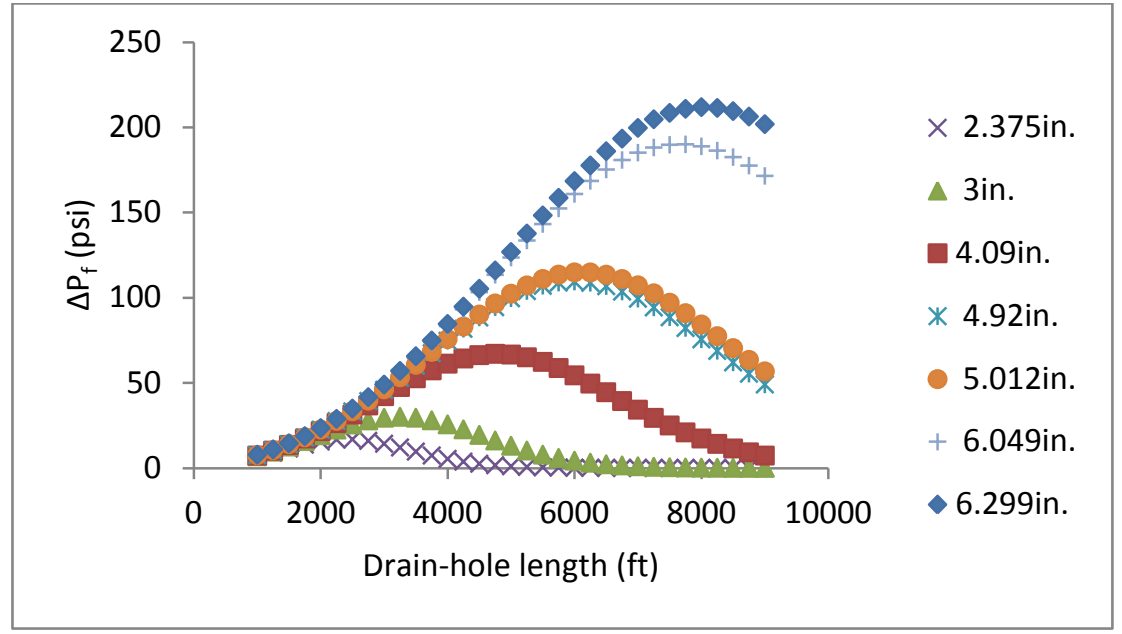

Figure 4. Friction pressure loss in 3in vertical section hole for various drain-hole diameter inflow performance at increasing drain-hole length.

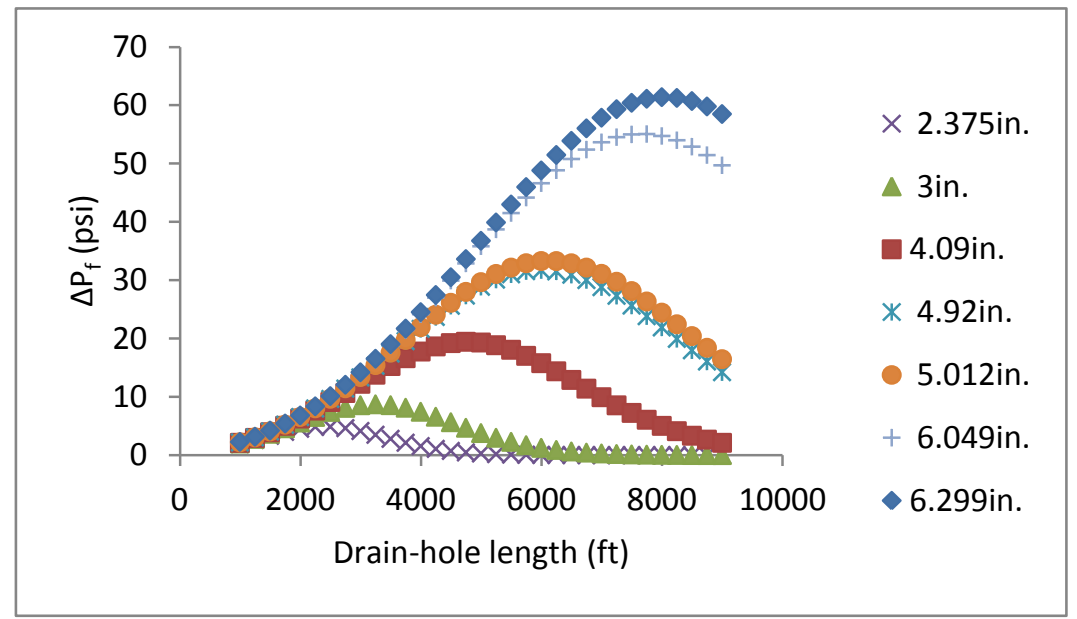

Figure 5. Friction pressure loss in 4.09in vertical section hole for various drain-hole diameter inflow performance at increasing drain-hole length.

light of the above, Figure $3-7$ give the corresponding pressure drop due to friction, noting that vertical hole section diameter should not be too small. However, the flow rate accounts for steady state performance knowing that boundary pressure shall eventually decrease with time and that the influence of relative permeability shall also reduce produced oil but with increasing water cut thereby dynamic modeling/optimization is required for improved analysis. The figures also show a geometric decrease in friction loss when increasing the vertical hole section diameter, this is evident from the equation.

Case-3: Pressure drop in the vertical section is optimized, held static at constant bottom-hole and tubing head flowing pressure at varying oil rate at the heel of the horizontal well for different drain- hole diameter and vertical section diameter. This enables the link between inflow and vertical lift performance to optimize drain-hole diameter and the corresponding oil production rate. Optimal length is given in Table 3 and plotted in Figure 8. It turns out that apart from the vertical section hole diameter of 2.375in, the influence of other pipe or hole diameter are similar. However, this does not include evaluation based on economics by optimizing NPV which consist of revenue and expenditure. Quite a similar trend is observed for the case of flow rate at the heel that is associated with the optimized drain-hole length. Figure 8 was as a result of maximizing the pressure drop in the vertical section towards a set target, while Figure 9 is generated by optimizing NPV and setting the pressure drop as a constraint to be met. The 
Table 3. Optimal drain-hole length $\left(L_{h}\right)$ as a function of drain-hole diameter $\left(D_{h}\right)$ and vertical hole section diameter $\left(D_{v}\right)$.

\begin{tabular}{cccccccc}
\hline \multirow{2}{*}{$D_{h}$} & \multicolumn{7}{c}{ Length } \\
\cline { 2 - 8 } in & $D v$ & $D v$ & $D v$ & $D v$ & $D v$ & $D v$ & $D v$ \\
& $2.375 \mathrm{in}$ & $3.000 \mathrm{in}$ & $4.090 \mathrm{in}$ & $4.920 \mathrm{in}$ & $5.012 \mathrm{in}$ & $6.049 \mathrm{in}$ & $6.299 \mathrm{in}$ \\
\hline 2.375 & 2407.15 & 2407.15 & 2407.15 & 2407.15 & 2407.15 & 2407.15 & 2407.15 \\
3.000 & 3254.47 & 3254.47 & 3254.47 & 3254.47 & 3254.47 & 3254.46 & 3254.46 \\
4.090 & 4786.17 & 4786.17 & 4786.17 & 4786.17 & 4786.17 & 4786.17 & 4786.17 \\
4.920 & 4633.45 & 5987.00 & 5987.00 & 5987.00 & 5987.00 & 5987.00 & 5986.99 \\
5.012 & 4559.18 & 6121.85 & 6121.85 & 6121.85 & 6121.85 & 6121.85 & 6121.85 \\
6.049 & 4212.38 & 7500.00 & 7500.00 & 7500.00 & 7500.00 & 7500.00 & 7500.00 \\
6.299 & 4175.47 & 7500.00 & 7500.00 & 7500.00 & 7500.00 & 7500.00 & 7500.00 \\
\hline
\end{tabular}

optimal drain-hole length is independent of vertical hole section diameter till a particular drain-hole diameter for both figures. However, from that drain-hole diameter there is sharp decline in drainhole length for the lowest vertical hole section diameter and the next increase diameter shows the highest drain-hole length that corresponds to increase in drain-hole diameter. This is associated with the same trend for flow rate but different for NPV. NPV from the particular drain-hole diameter increases with increase in vertical hole section diameter. The trends are difficult to interpret; however, the trend is indicative of the impact of well construction cost that would have been affected by pipe/hole diameter. Hence, the inclusion of pipe/hole diameter is required as a variable in well construction cost.
This study has essentially made assumptions for general simplification. However, the procedure established here is beneficial for expanding applications to cover cases of multiphase flow in the vertical wellbore leading to multi-segmented solution and issues of possible liquid-holdup. For single phase flow, as in black oil, formation volume factor changes with pressure. Following the same guidelines, a study should investigate different bottom-hole flowing pressures. The dynamic variables should not be limited. A composite system comprising all pressure drops from the horizontal well toe through the heel to the choke through the tubing head flowing pressure should be optimized for a holistic approach. However, the variables and pressure drops considered in this study are of major concern.

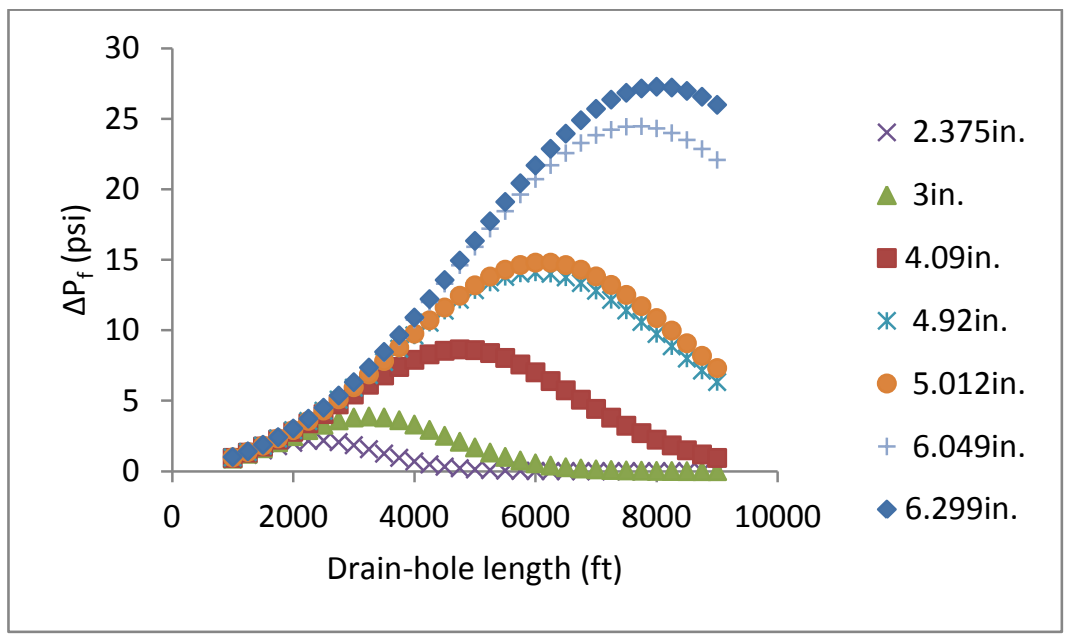

Figure 6. Friction pressure loss in 5.012in vertical section hole for various drain-hole diameter inflow performance at increasing drain-hole length. 


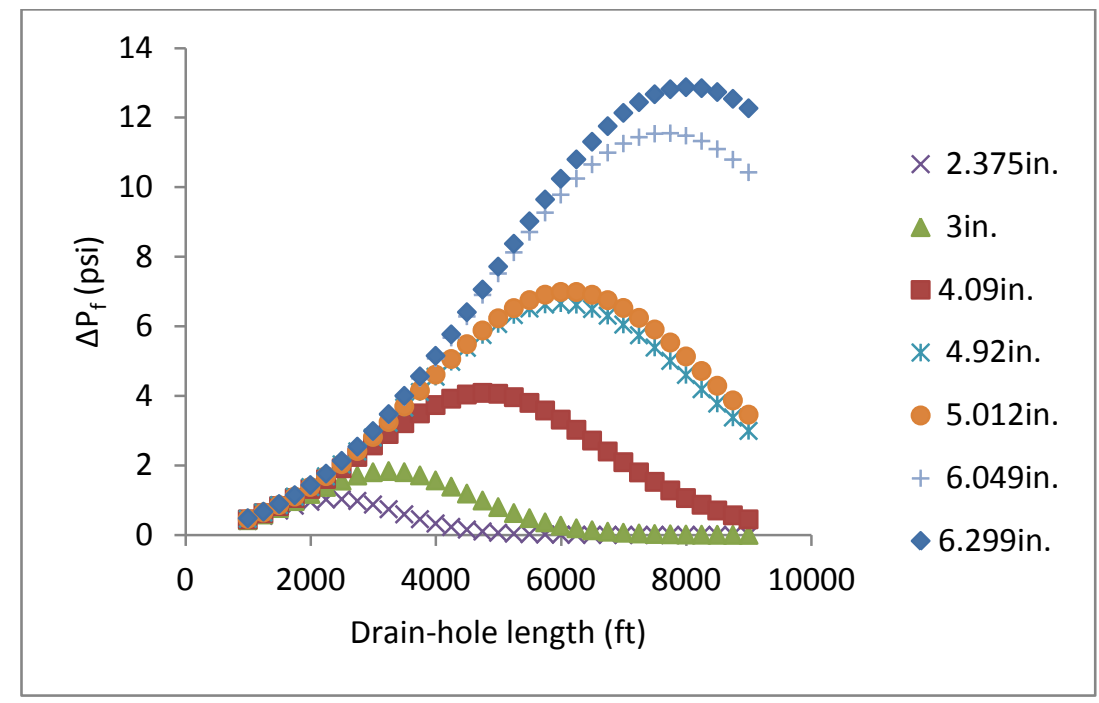

Figure 7. Friction pressure loss in 6.049in vertical section hole for various drain-hole diameter inflow performance at increasing drain-hole length.

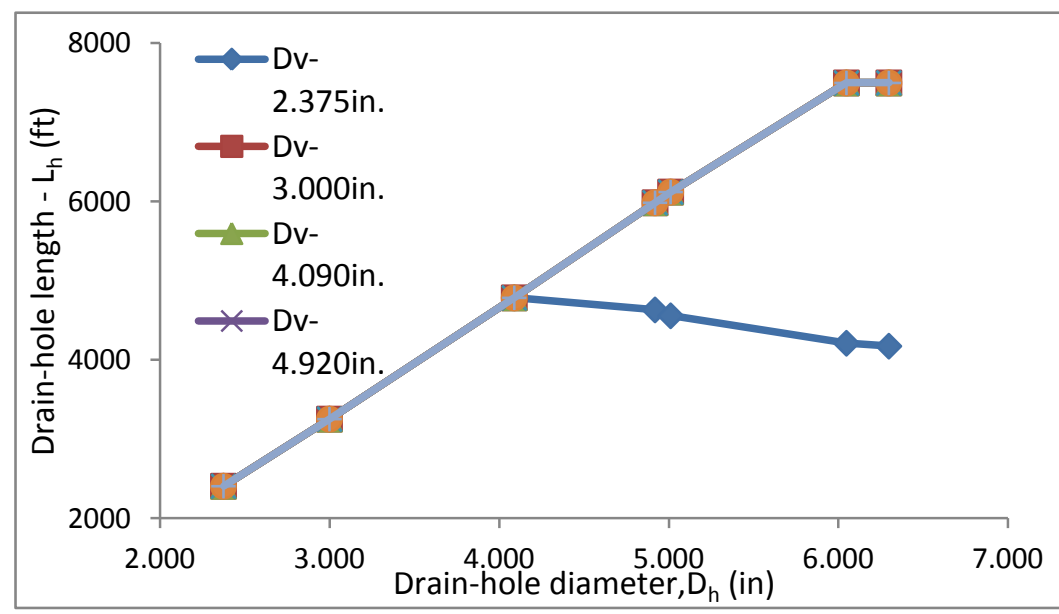

Figure 8. Optimal drain-hole length $\left(L_{h}\right)$ as a function of drain-hole diameter $\left(D_{h}\right)$ and vertical hole section diameter $\left(D_{v}\right)$.

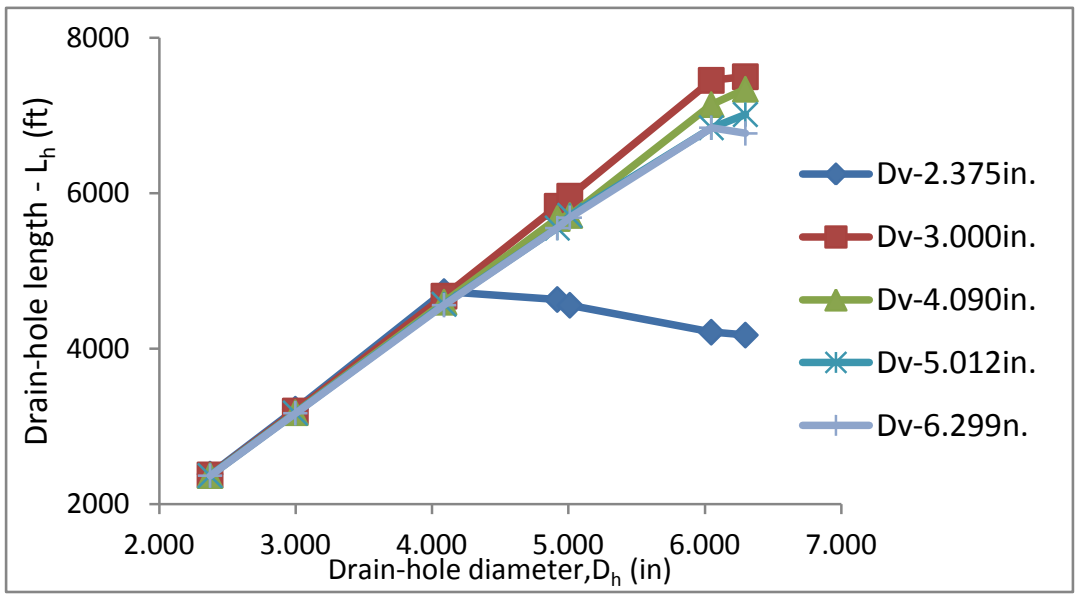

Figure 9. Optimal drain-hole length $\left(L_{h}\right)$ as a function of drain-hole diameter $\left(D_{h}\right)$ and vertical hole section diameter $\left(D_{v}\right)$ based on maximizing NPV. 


\section{CONCLUSIONS}

Choosing the right drain-hole length for a horizontal well requires optimizing a function that incorporates flow resistance as well as the economics of recovery and production. In carrying out this study, the following pertinent points were observed:

- Composite analysis that incorporates the entire pressure drop of a well system as in nodal analysis, required to appropriately maximize tubing / (vertical wellbore performance) and inflow performance; hence, drain-hole length.

- Evaluating optimal drain-hole length without incorporating drain-hole diameter and vertical hole section diameter under net present value (NPV) as the objective function to maximize returns may not give the desired result. There was a significant difference between optimizing NPV and vertical wellbore pressure drop to obtain optimal drain-hole length.

- The drain-hole diameter and vertical section diameter are constrained to well plan. Possible eventualities need to be solved or remedied in the course of executing the well program.

\section{NOMENCLATURE}

$\mathrm{a}=$ half major axis of drainage ellipse

$\mathrm{A}=$ unit construction cost

$\mathrm{b}=$ decline exponent

$\mathrm{B}=$ fixed cost

$\mathrm{B}_{\mathrm{o}}=$ oil formation volume factor

CAPEX = capital expenditure

$\mathrm{C}_{\mathrm{beh}}=$ cost of bits for horizontal section

$\mathrm{C}_{\text {bev }}=$ cost of bits for vertical section

$\mathrm{C}_{\mathrm{cph}}=$ well completion cost horizontal section

$\mathrm{C}_{\mathrm{cpv}}=$ well completion cost vertical section

$\mathrm{C}_{\mathrm{r}}=$ rig cost

$\mathrm{D}=$ decline rate

$\mathrm{D}_{\mathrm{h}}=$ drain hole diameter

$D_{v}=$ diameter of vertical section

$\mathrm{f}=$ Darcy-Weisbach (Moody) friction factor

$\mathrm{g}_{\mathrm{c}}=$ conversion factor

$\mathrm{h}=$ formation thickness

$\mathrm{i}_{\mathrm{D}}=$ discount rate

$\mathrm{J}_{\mathrm{s}}(\mathrm{x})=$ productivity index per unit length $\mathrm{k}_{\mathrm{h}}=$ horizontal permeability

$\mathrm{k}_{\mathrm{v}}=$ vertical permeability

$\mathrm{L}_{\mathrm{h}}(\mathrm{ft})=$ drain hole length

$\mathrm{L}_{\mathrm{v}}=$ vertical section of horizontal well

$\mathrm{n}=$ construction cost exponent

$\mathrm{Np}=$ cumulative production

$\mathrm{N}_{\mathrm{RE}}=$ Reynolds number

OPEX $=$ operating expenditure

Po $=$ oil price

$\mathrm{P}_{\mathrm{tf}}=$ tubing head flowing pressure

$\mathrm{P}_{\mathrm{wf}}=$ bottom hole flowing pressure at heel

$\mathrm{q}=$ production rate at time $\mathrm{t}$ (oil production rate with friction loss)

$\mathrm{q}^{\prime}=$ oil production rate without friction loss

$\mathrm{q}_{\mathrm{i}}=$ initial production rate

$\mathrm{r}^{\prime}{ }_{\mathrm{w}}=$ effective wellbore radius in anisotropic

$\mathrm{R}_{\mathrm{eh}}=$ horizontal well drainage radius

$\mathrm{Rs}=$ flow resistance of the drain hole

$\mathrm{r}_{\mathrm{w}}=$ wellbore radius

$\mathrm{t}=$ time

$\mathrm{t}_{\mathrm{lh}}=$ time for vertical section drilling

$\mathrm{t}_{\mathrm{lv}}=$ time for vertical section drilling

$\mathrm{V}=$ vertical section flow velocity

$\mu=$ oil viscosity

$\alpha=$ empirical coefficient for flow resistance

(economics - variable oil production cost)

$\beta=$ anisotropy

$\gamma=$ fixed production cost multiplier per year

$\Delta \mathrm{P}_{\mathrm{f}}=$ friction loss

$\Delta \mathrm{P}_{\mathrm{h}}=$ drawdown at the heel of the well

$\Delta \mathrm{P}_{\mathrm{PE}}=$ potential energy pressure drop

$\pi=3.14$

$\rho=$ oil density

$\rho_{\mathrm{o}}=$ oil density

\section{REFERENCES}

Bosio, J. C.; Fincher, R. W.; Giannesini, J. F.; Hatten, J. L. Horizontal drilling-A new production method. Proceedings $12^{\text {th }}$ World Petroleum Congress, Houston, Texas, April 1987.

Cho, H.; Shah, S. N. Optimization of well length for horizontal drilling. Journal of Canadian Petroleum Technology, v.41, p. 54-63, 2002. http://dx.doi.org/10.2118/02-05-03 
Dikken, B. J. Pressure drop in horizontal wells and its effect on production performance. Journal Petroleum Technology, v.42, p. 1426-1433, 1990. http://dx.doi.org/10.2118/19824-PA

Fadairo, A. S.; Ako, C.; Falode O. Modeling productivity index for long horizontal well. Journal of Energy Resources Technology, v.133, p. 033101_1-033101_8, 2011.

Fetkovich, M. J. Decline curve analysis using type curves. AIME-SPE 4629, $48^{\text {th }}$ Annual fall meeting of SPE of AIME held in Las Vegas, NV, September 30 - October 3, 1973.
Orodu, O. D.; Tang, Z.; Anawe, P.A.L. Sidetrack and recompletion risk evaluation - Waterflooded reservoir. Journal of Petroleum Science and Engineering, v.78, p. 705-718, 2011. http://dx.doi.org/10.1016/i.petrol.2011.08.015

Renard, G.; Dupuy, J.M. Formation damage effects on horizontal-well flow efficiency. Journal of Petroleum Technology, v.43, p. 786-789, 868-869, 1991. 